Disclosure of Interest: G. Goll Consultant for: AbbVie, Biogen, Boehrinfer Ingelheim, Orion Pharma, Eli Lilly, Novartis, PfizerMSD, Roche, UCB, K. Jørgensen Consultant for: Tillott, Celltrion, Intercept, J. Sexton: None declared, I. Olsen Consultant for: Pfizer, N. Bolstad Consultant for: Pfizer, Orion Pharma, Napp pharmaceuticals, Takeda, M. Lorentzen: None declared, E. Haavardsholm Consultant for: AbbVie, Pfizer, MSD, Roche, UCB, C. Mørk Consultant for: AbbVie, Novartis, LEO Pharma AS, ACI hud Norge, Cellgene AS, Galderma Nordic AB, J. Jahnsen Consultant for: AbbVie, Celltrion, Takeda, Napp Pharm, AstroPharma, Hikma, Orion Pharma, Pfizer, T. Kvien Consultant for: AbbVie, Biogen, Eli Lilly, Novartis, Pfizer, MSD, Roche, UCB, Boehringer Ingelheim, Epirus, JAnssen, MerckSerono, Mundipharma, Oktal, Orion Pharma DOI: 10.1136/annrheumdis-2018-eular.4620

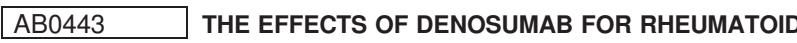 ARTHRITIS PATIENT}

1. Yoshii. Rheumatology and Musculoskeletal Medicine, YOSHII HOSPITAL, Shimanto City, Japan

Background: Denosumab (dMAB), an anti-receptor activator of nuclear factor kappa-B ligand (RANKL) monoclonal antibody, is now popular anti bone absorption suppressant for osteoporosis. Recently, this drug has indicated for rheumatoid arthritis (RA) treatment, for expectance for suppressant in joint destruction. However, except of the effect on joint deformation, anti inflammation effect is not evident in randomised control trial (RCT), although rich case series for OP in RA patient is already collected in clinical practice.

Objectives: Aim of this study is to investigate effects of dMAB on RA, and evaluate other effects but joint destruction suppression.

Methods: In 352 patients who have been treated with dMAB, RA patients who have been treated with $\mathrm{dMAB}$ consecutively for more than 1 year, were picked up for this study. Patient who have had experience of biologic disease modifying anti rheumatic drug (bDMARD) or targeted synthetic DMARD, had been eliminated. In whom bone mineral density (BMD) in lumbar spine (LS), femoral neck (FN), and greater trochanter (GT), and tartrate-resistant acid phosphatase $5 b$ (TRACP5b), 28-joints disease activity score with C-reactive protein (DAS28-CRP), Health Assessment Questionnaire Disease Index (HAQ-DI), yearly progression of Sharp/van der Heijde score (dSHS), joint space narrowing score (dJSN) and bone erosion score (dBE), and pain score with visual analogue scale (PS-VAS) were measured, and their mean values were compared between 6 months before start (BEF) and 6 months after start (AFT) statistically with paired T-test. Statistically significant level was set less than $1 \%$.

Results: One hundred and three patients, in whom 100 were female and three were male, were donated in this study. All of them had been supplemented with Denotas Chewable Combination Tablets (Daiichi Sankyo Co., Ltd; Tokyo, Japan), which is medical compound with calcium and natural vitamin $D_{3}$. Average age at start was 71.17 years old, and disease duration of RA at start was 7.42 years. Glucocorticoid was administered in 45 patients $(44.7 \%)$, and methotrexate was administered in 72 patients $(69.9 \%)$. BMD demonstrated from 74.03 (\%YAM) to 77.32 in LS, whereas from 69.79 to 69.63 in FN, and from 71.99 to 74.27 in GT, from BEF to AFT, respectively. BMD of LS and GT at AFT demonstrated significant increase, while FN demonstrated no significant difference. TRACP5b demonstrated 489.3 at BEF, while 255.3 at AFT. TRACP5b at AFT demonstrated significant less value than at BEF. Disease activity, namely DAS28-CRP, tenderness joint count (TJC), swollen joint count (SJC), patient's global assessment $(P G A)$, evaluator's global assessment (EGA), CRP, pain score with visual analogue scale (PS-VAS), HAQ-DI, SHS, JSN, and BE from BEF to AFT demonstrated 2.12 to $1.86,1.32$ to $0.89,2.13$ to $0.97,2.23$ to $2.01,1.27$ to $0.68,0.80$ to $0.70,0.537$ to $0.590,81.76$ to $80.98,36.16$ to $37.08,46.96$ to 44.27 , respectively. DAS28-CRP, and all of its components, and EGA demonstrated significant decrease, although PS-VAS showed decrease yet demonstrated no significance, while HAQ-DI showed increase with no statistical significance. dSHS and dBE demonstrated significant less at AFT than at BEF, while no significance for dJSN yet slightly increased in the AFT, even no significant difference demonstrated for absolute values (table 1 ).
Abstract AB0443 - Table 1. Change of each parameters and statistical significance. BMD, bone mineral density; \% YAM, percentage of young adult mean value; BEF, before administration of denosumab; AFT, first value after denosumab was administered; S.S., statistical significance; LS, average value of lumbar spine from L1 to L4; FN, femoral neck; GT, greater trochanter; DAS28-CRP, 28-joints disease activity score with C-reactive protein; TJC, tenderness joint count; SJC, swolen joint count; PGA, patient's global assessment; CRP, C-reactive protein; EGA, evaluator's global assessment; PS-VAS, pain score with visual analogue scale; HAQ-DI, Health Assessment Questionnaire Disability Index; SHS, Sharp/van der Heijde Score; JSN, joint space narrowing score; BE, bone erosion score; $n$ s., not significant; *, AFT is statistically significantly smaller than BEFwithin $1 \%$; §, BEF is statistically significantly larger than AFT within $1 \%$.

\begin{tabular}{|r|c|c|c|}
\hline BMD (\%YAM) & BEF & AFT & S.S. \\
\hline LS & $74.03 \pm 15.74$ & $77.32 \pm 15.79$ & $*$ \\
\hline FN & $69.79 \pm 11.65$ & $69.63 \pm 11.93$ & ns. \\
\hline GT & $71.99 \pm 13.82$ & $74.27 \pm 13.28$ & $*$ \\
\hline TRACP-5b & $489.3 \pm 214.4$ & $255.3 \pm 133.6$ & $\S$ \\
\hline DAS28-CRP & $2.12 \pm 0.91$ & $1.86 \pm 0.72$ & $*$ \\
\hline TJC & $1.32 \pm 2.20$ & $0.89 \pm 1.99$ & $*$ \\
\hline SJC & $2.13 \pm 3.54$ & $0.97 \pm 1.85$ & $*$ \\
\hline PGA & $2.23 \pm 2.30$ & $2.01 \pm 1.88$ & $*$ \\
\hline CRP & $0.80 \pm 1.55$ & $0.70 \pm 1.36$ & ns. \\
\hline EGA & $1.27 \pm 1.64$ & $0.68 \pm 1.07$ & $*$ \\
\hline PS-VAS & $28.34 \pm 23.32$ & $27.07 \pm 21.65$ & ns. \\
\hline HAQ-DI & $0.537 \pm 0.611$ & $0.590 \pm 0.648$ & $\S$ \\
\hline SHS & $81.76 \pm 89.36$ & $80.98 \pm 89.65$ & ns. \\
\hline JSN & $36.16 \pm 37.76$ & $37.08 \pm 38.57$ & $\S$ \\
\hline BE & $45.96 \pm 53.08$ & $44.27 \pm 52.18$ & $*$ \\
\hline & & & \\
\hline
\end{tabular}

Conclusions: The effect of $\mathrm{dMAB}$ on RA is suggested suppression of $\mathrm{dBE}, \mathrm{BMD}$ increase in LS and GT, improvement of DAS28-CRP, and may have decrease of PS-VAS.

Disclosure of Interest: None declared

DOI: 10.1136/annrheumdis-2018-eular.1903

\section{AB0444 DESCRIPTION IN REAL-WORLD OF THE EFFICACY AFTER SWITCHING FROM INTRAVENOUS TO SUBCUTANEOUS ADMINISTRATION OF TOCILIZUMAB IN PATIENTS WITH RHEUMATOID ARTHRITIS. THE ROSWITCH STUDY}

J. Darloy ${ }^{1}$, N. Segaud ${ }^{2}$, J.-H. Salmon ${ }^{3}$, V. Goeb ${ }^{4}$, M.-H. Guyot ${ }^{5}$, L. Marguerie ${ }^{6}$, C. Chopin ${ }^{7}$, S. Gally ${ }^{8}$, I. Idier ${ }^{9}$, G. Baudens ${ }^{10}$, R.-M. Flipo ${ }^{11} .{ }^{1}$ Rheumatology, University Hospital, Lille; ${ }^{2}$ Rheumatology, General Hospital, Armentières; ${ }^{3}$ Rheumatology, University Hospital, Reims; ${ }^{4}$ Rheumatology, University Hospital, Amiens; ${ }^{5}$ Rheumatology, General Hospital Victor Provo, Roubaix; ${ }^{6}$ Rheumatolgy, Institut Francois Calot, Berck-sur-Mer, ${ }^{7}$ Rheumatology, University Hospital Maison Blanche, Reims; ${ }^{8}$ Clinical Operations, Roche SAS, Boulogne Billancourt, ${ }^{9}$ Medical, Chugai Pharma France, Paris La Defense; ${ }^{10}$ Rheumatology, Private Practice, Valenciennes; ${ }^{11}$ Rheumatology, University Hospital Roger Salengro, Lille, France

Background: It has been proven, in a pivotal RCT, that SC tocilizumab (TCZ) was non-inferior to IV TCZ. ${ }^{1}$ However the switch from IV to SC TCZ has not been evaluated to date in a large real-world study.

Objectives: The main objective was to assess the maintenance of efficacy of SC TCZ 6 months (M6) after switching from IV to SC formulation in patients (pts) with rheumatoid arthritis (RA) in real-world. Secondary objectives were: characteristics of pts and RA, efficacy of TCZ at M12, TCZ retention rates at M6 and M12 for Switch (IV-SC) and No-Switch pts (IV-IV), predictive factors of switching.

Methods: We analysed all RA pts of the shared medical file "RIC Nord de France" with $\geq 1$ DAS 3 months before inclusion, treated with TCZ, switching or not from IV to SC TCZ, between April 302015 and January 152016 . The primary efficacy endpoint was the\% of pts remaining in their DAS28-ESR category remission/LDA or moving to an inferior DAS category at M6. Various sensibility analyses were realised on the primary criterion of which a propensity score (IPTW).

Results: From the 314 included pts, $30 \%$ switched from IV to SC TCZ. At baseline, $77.7 \%$ were females, mean BMI was $27.5 \pm 6.4$, mean RA duration was 14.9 \pm 9.2 years. Mean IV TCZ duration before inclusion was $35.0 \pm 23.1$ months in Switch and 26.8 \pm 22.1 months in No-Switch pts. Mean DAS28 were 2.1 \pm 1.1 in Switch and $2.9 \pm 1.6$ in No-Switch pts. $81.9 \%$ and $59.5 \%$ of the pts were in DAS28 remission/LDA, $18.1 \%$ and $28.6 \%$ in MDA, $0 \%$ and $11.8 \%$ in HAD in Switch and 
No-Switch pts respectively. The improvement of initial DAS28-ESR category or maintenance in remission/LDA was comparable in both groups at M6 and M12 (table 1).

Abstract AB0444 - Table 1. DAS28-ESR improvement or maintenance in remission/LDA category

\begin{tabular}{lcc}
\hline$\%$ of $\mathrm{pts}^{*}, 95 \% \mathrm{Cl}$ & Switch, $\mathrm{n}=94$ & No Switch, $\mathrm{n}=220$ \\
\hline $\mathrm{M} 6, \mathrm{n} / \mathrm{N}$ & $66 / 90$ & $137 / 195$ \\
& $73.3 \%[63.0-82.1]$ & $70.3 \%[63.3-76.6]$ \\
$\mathrm{M} 12, \mathrm{n} / \mathrm{N}$ & $63 / 91$ & $118 / 204$ \\
& $69.2 \%[58.7-78.5]$ & $57.8 \%[50.8-64.7]$ \\
\hline
\end{tabular}

* Permanent discontinuation of TCZ considered as failure.

Using the IPTW for balancing on baseline characteristics between groups, similar proportions were observed at both M6 and M12. TCZ retention rates at M12 were $78 \%$ (95\% Cl ${ }^{68-85}$ and $80 \%$ (95\% Cl: $74-85 \mathrm{p}=0.555$ for Switch and No-Switch groups respectively. In the 208 pts with a DAS28 $\leq 3.2$ at inclusion, multivariate analysis showed no parameters associated to the switch. Conversely in the 106 pts with a DAS28 $>3.2$ at inclusion, rheumatoid nodules $(\mathrm{OR}=4.78,95 \% \mathrm{Cl}[1.23-$ 18.55], $\mathrm{p}=0.024)$ and duration of IV TCZ before inclusion (OR=1.37, $95 \% \mathrm{Cl}$ [1.08-1.73], $p=0.009$ ) were significantly associated to the switch.

Conclusions: The RoSwitch study showed the maintenance of efficacy at 6 and 12 months in RA pts switching from IV to SC TCZ. Similar efficacy and therapeutic retention rates were observed for No-Switch pts. No factor was associated with the switch in pts in remission/LDA at inclusion suggesting that patient's personal appreciation was preponderant in the choice of the switch.

\section{REFERENCES:}

[1] Burmester GR, et al. Ann Rheum Dis 2014 Jan;73(1):69-74

Disclosure of Interest: J. Darloy: None declared, N. Segaud: None declared, J.H. Salmon: None declared, V. Goeb: None declared, M.-H. Guyot: None declared, L. Marguerie: None declared, C. Chopin: None declared, S. Gally Employee of: Roche SAS, I. Idier Employee of: Chugai Pharma France, G. Baudens: None declared, R.-M. Flipo Consultant for: Roche. Chugai Pharma France

DOI: 10.1136/annrheumdis-2018-eular.3411

\section{AB0445 THERAPEUTIC MAINTENANCE OF ABATACEPT IN RHEUMATOID ARTHRITIS: RESULTS OF THE RIC-ABA STUDY (517 PATIENTS)}

J.H. Salmon ${ }^{1,2}$, J.G. Letarouilly ${ }^{3}$, P. Coquerelle ${ }^{4}$, V. Goeb ${ }^{5}$, M.H. Guyot ${ }^{6}$, E. Houvenagel ${ }^{7}$, N. Lecuyer ${ }^{8}$, L. Le Dantec ${ }^{9}$, L. Marguerie ${ }^{10}$, G. Morel $^{11}$, G. Baudens ${ }^{12}$, E. Solau ${ }^{13}$, R.-M. Flipo ${ }^{3} .{ }^{1}$ Rheumatology, Maison Blanche Hospital, Reims University Hospitals; ${ }^{2}$ University of Reims Champagne-Ardenne, Faculty of Medicine, EA 3797, Reims; ${ }^{3}$ Rheumatology, CHRU LIlle, Lille; ${ }^{4}$ Rheumatology, $\mathrm{CH}$ Bethune, Bethune; ${ }^{5}$ Rheumatology, $\mathrm{CHU}$ Amiens, Amiens; ${ }^{6}$ Rheumatology, $\mathrm{CH}$ Roubaix, Roubaix, ${ }^{7}$ Rheumatology, Hôpital Saint Philibert, Lomme;

${ }^{8}$ Rheumatology, Cabinet médical, Saint Quentin; ${ }^{9}$ Rheumatology, Cabinet médical, Liévin; ${ }^{10}$ Rheumatology, Institut Francois Calot, Berck-sur-Mer, ${ }^{11}$ Rheumatology, $\mathrm{CH}$ Valenciennes; ${ }^{12}$ Rheumatology, Cabinet médical, Valenciennes;

${ }^{13}$ Rheumatology, $\mathrm{CHU}$ Poitiers, Poitiers, France

Objectives: Study the therapeutic maintenance, associated factor with maintenance at 12 months and reasons for abatacept (ABA) stop in daily practice.

Methods: Retrospective multicentric study, from the RIC Nord de France network, of patients treated for rheumatoid arthritis who received at least one ABA treatment between January 2008 and July 2016. We studied the therapeutic maintenance at 12 months, according to the number of previous bDMARDs and according to the date of initiation (group 1: from 2008 until 31/07/2010 (ABA authorised in anti-TNFfailure) and group 2 from 01/08/2010 (ABA authorised in the first line)). Therapeutic maintenance was evaluated using the Kaplan-Meier method.

Results: Of the 517 patients ( $74 \%$ women) who were included, the mean age was $61.4 \pm 13.3$ years. There were $76 \%$ positive anti-CCP. ABA was used as monotherapy in 176 patients (34\%) and $22 \%$ of patients were naïve to bDMARDs. The mean DAS 28 -VS at initiation of ABA was $4.7 \pm 1.3$.

Therapeutic maintenance at 12 months was $68 \%$. Among the 166 patients (32\%) stopped ABA, the reason for discontinuation was primary ineffectiveness $(n=54$, $32.5 \%)$, loss of efficacy $(n=40,24 \%)$, adverse events $(n=43,26 \%)$ and other $(n=29,17.5 \%)$. On multivariate analysis CRP $<10 \mathrm{mg} / \mathrm{L}$ was associated with better maintenance at 12 months.

No significant difference in therapeutic maintenance was found at 12 months according to the date of initiation and according to the number of previous bDMARDs.

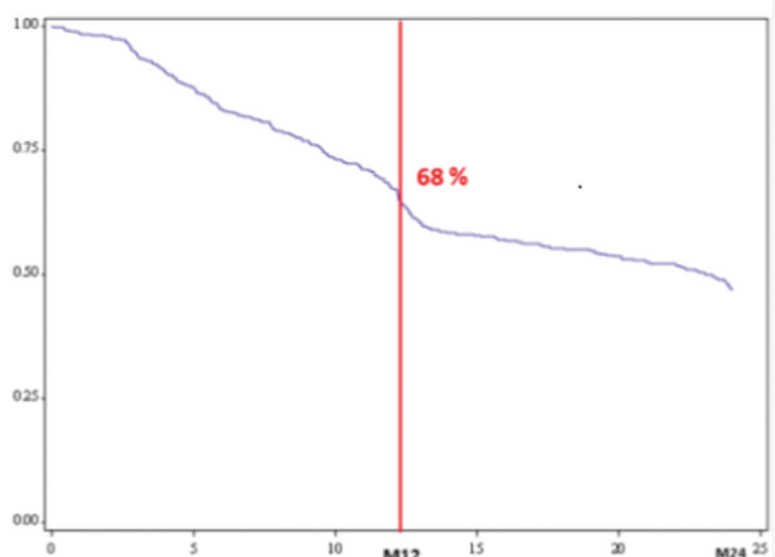

Abstract AB0445 - Figure 1. Therapeutic maintenance of Abatacept at 12 months

Conclusions: Therapeutic maintenance at 12 months was $68 \%$, this rate is similar to Pan-European Registry. The rate of CRP at initiation seems to have an impact on the maintenance of $A B A$ at 12 months.

\section{REFERENCE:}

[1] Gottenberg JE, Courvoisier DS, Hernandez MV, lannone F, Lie E, Canhão $\mathrm{H}$, et al. Brief Report: Association of Rheumatoid Factor and Anti-Citrullinated Protein Antibody Positivity With Better Effectiveness of Abatacept: Results From the Pan-European Registry Analysis. Arthritis Rheumato 2016 Jun;68(6):1346-52. doi:10.1002/art.39595

Disclosure of Interest: None declared

DOI: 10.1136/annrheumdis-2018-eular.4440

\section{AB0446 PHYSICIAN-REPORTED BEHAVIOURS AND TREATMENT TRENDS OF TUMOUR NECROSIS FACTOR INHIBITOR USE: CYCLING VERSUS SWITCHING IN FIVE EUROPEAN COUNTRIES: FRANCE, GERMANY, ITALY, SPAIN AND THE UK}

J.R. Curtis ${ }^{1}$, E. Sullivan ${ }^{2}$, J. Kershaw ${ }^{2}$, S. Blackburn ${ }^{2}$, P. Mahajan ${ }^{3}$, S. Boklage ${ }^{4}$. ${ }^{1}$ University of Alabama at Birmingham, Birmingham, USA; ${ }^{2}$ Adelphi Real World, Manchester, UK; ${ }^{3}$ Sanofi, Bridgewater, ${ }^{4}$ Regeneron Pharmaceuticals, Inc., Tarrytown, USA

Background: Previously, most biologics prescribed for treating rheumatoid arthritis (RA) were tumour necrosis factor inhibitors (TNFi) and it was common practice to prescribe a second TNFi after failure of the first. Biologics with different mechanisms of action (MOA) have become available and 2016 European League Against Rheumatism guidelines recommend cycling to another TNFi or switching to a biologic with a new MOA following failure of the first TNFi.

Objectives: Describe the proportion of patients in $5 \mathrm{EU}$ countries who, after failure of a first TNFi, cycle to a second TNFi ('TNFi cycling') vs switch to a treatment with a different MOA ('Switch'), and identify patient characteristics and physician attitudes associated with TNFi cycling vs switching

Methods: Data were from the Adelphi Disease Specific Programme (DSP), a cross-sectional survey conducted in 2017 in France, Germany, Italy, Spain and the UK. Rheumatologists prospectively completed records about the next 10 patients with RA who consulted them during the study period; records captured treatment history and clinical details. Patients were included in the analysis if they had been prescribed at least 2 different biologics, their first was a TNFi and their second was known. Patients were assigned to 2 cohorts: 'TNFi cycling' patients received a TNFi at first- and a different TNFi at second-line; 'Switch' patients received a TNFi at first-line and a non-TNFi at second-line. Bi-variate comparisons of groups were conducted using nonparametric tests as appropriate.

Results: All physicians in the DSP sample $(n=301)$ were questioned on thei beliefs around TNFis; $86.4 \%$ believed that there is a class effect with TNFis regarding efficacy and/or safety (table 1). Data from 359 patients were included in the analysis (75.8\% female; mean [SD] age 56.5 [12.7]), of whom $167(46.5 \%)$ were TNFi cycling, and 192 (53.5\%) were Switch patients (female: $70.7 \%$ vs $80.2 \%$, respectively; $p=0.04$; age: 55.8 [13.1] vs 57.1 [12.4], respectively; $p=0.42$ ) The most common reasons for discontinuing first-line therapy among the TNF cycling and Switch cohorts were worsening condition (36.3\% vs $45.3 \%$, 